\title{
Errata and corrigenda
}

On p. 100 of the article,

Wookey P.A. 2007. Climate change and biodiversity in the Arctic-Nordic perspectives. Polar Research 26(2), 96-103,

Figs. 6 and 7 (shown below) were correctly attributed to Walker et al. 2006 but that the captions mistakenly indicate that the article was originally published in a MacMillan Magazine. Walker et al. 2007 appeared in the Proceedings of the National Academy of Sciences, which is published by National Academy of Sciences, USA. The National Academy of Sciences has kindly granted Polar Research permission to reproduce the illustrations in question and the figure captions have been corrected in the online version of Wookey's article.
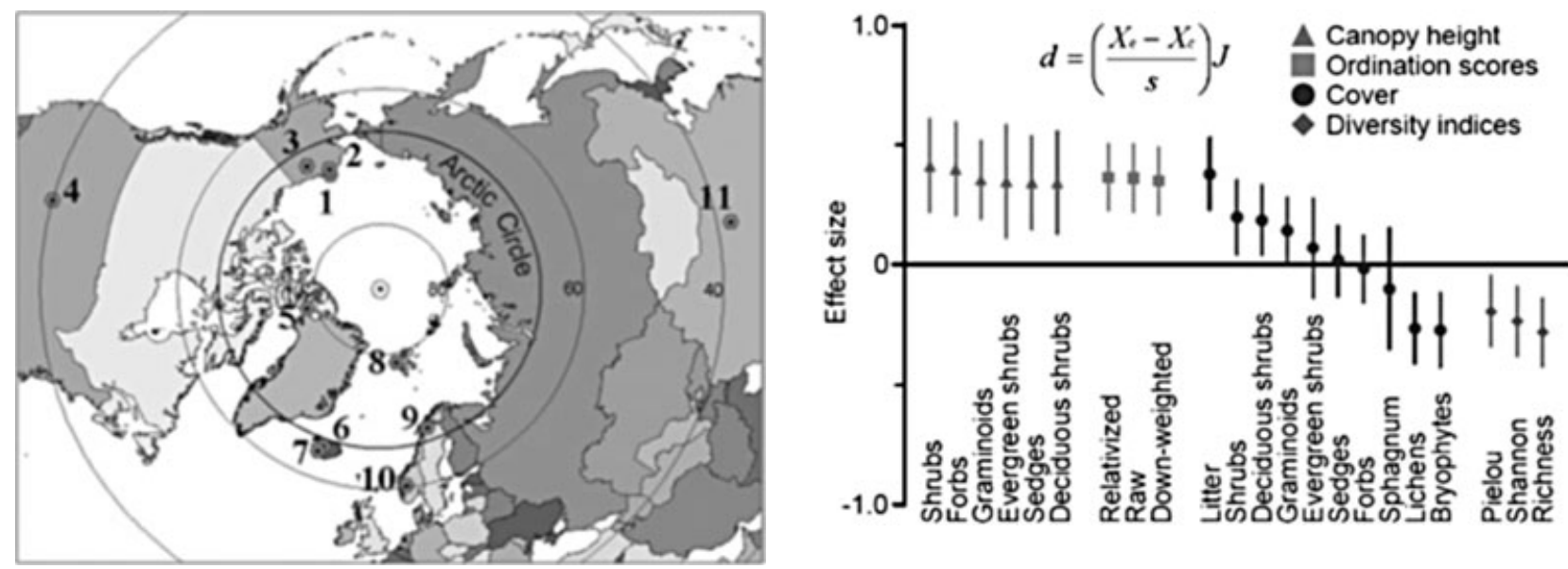

On p. 112 of the article,

Bäsemann H.B 2007. Melting ice-a personal view of climate change. Polar Research 26(2), 107-112,

the url for the photographer's website contained an error. The correct url is www.polarfoto.com.

On p. 156 of the article,

Cottier F.R. \& Venables E.J. 2007. On the double-diffusive and cabbeling environment of the Arctic Front, west Spitsbergen. Polar Research 26(2), 152-169,

the figure component that is labelled $4 \mathrm{a}$ should have been labelled $4 \mathrm{~b}$ and what is labelled $4 \mathrm{~b}$ should have been $4 \mathrm{a}$.

On p. 103 of the article,

Kohler J., Brandt O., Johansson M. \& Callaghan T. 2006. A long-term Arctic snow depth record from Abisko, northern Sweden, 1913-2004. Polar Research 25(2), 91-113,

Fig. 8 was not the correct figure. The correct figure appears below. The online version of the article has been corrected and is freely available online. 

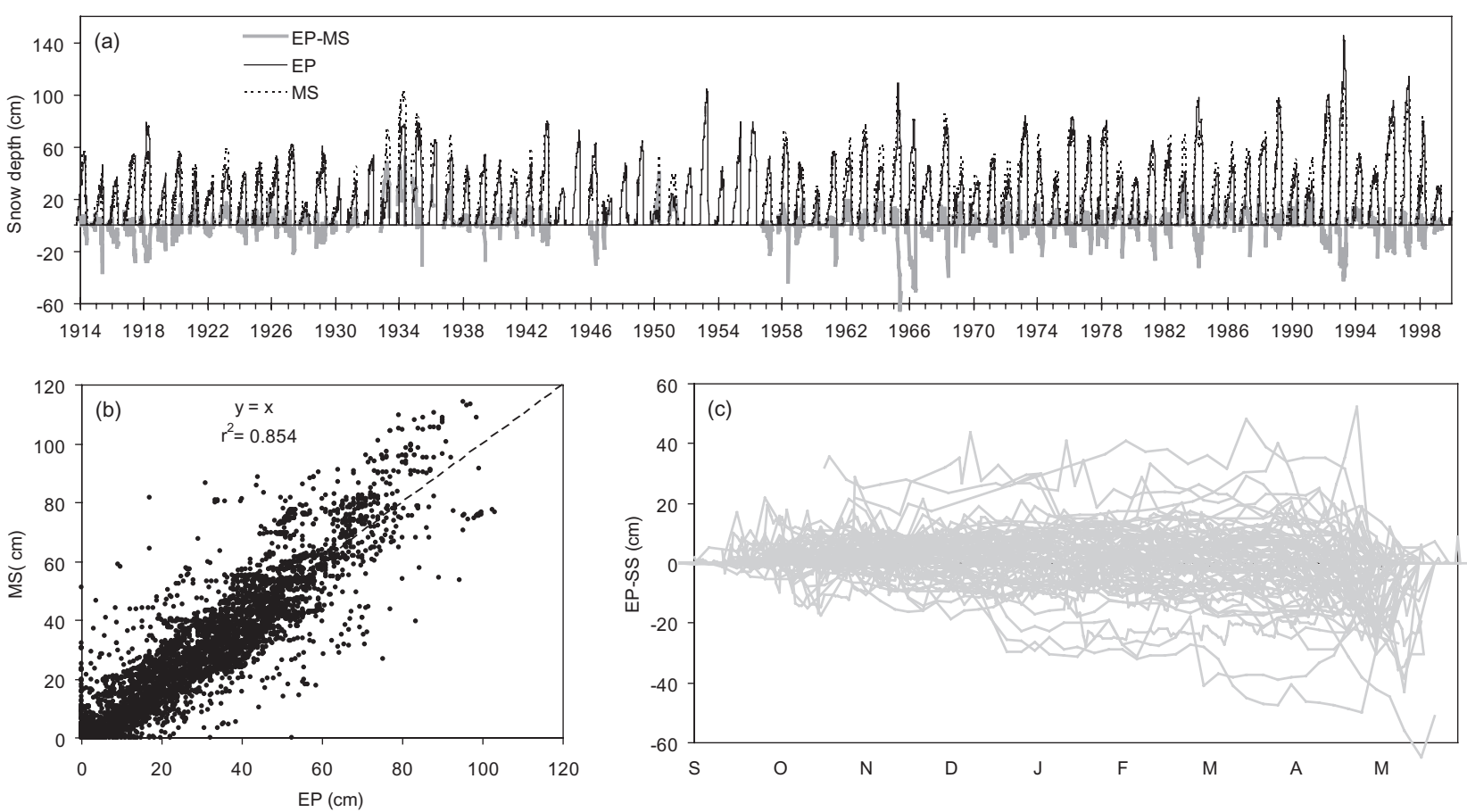